\title{
Canada needs seniors' health care strategy: CMA report card
}

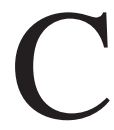
anada's doctors called for a national strategy to provide long-term health care for seniors as they kicked off their 146th annual general meeting in Calgary, Alberta, with a focus on end-of-life and palliative assistance.

Aug. 18, on the cusp of its three-day meeting, the Canadian Medical Association (CMA) called on all levels of government to cooperate in creating a seniors' strategy, citing the looming pressure aging baby boomers will place on the health-care system.

"The anxiety Canadians have about health care in their so-called golden years is both real and well-founded," Dr. Anna Reid, then-CMA president, said in a news release. "Let there be no doubt that a national strategy for seniors' health care should be a federal priority."

The statement accompanied the release of the CMA's 13th Annual National Report Card on Health Care. The CMA hired Ipsos Reid to survey 1000 Canadians aged 18 and over about seniors' health care. The poll also asked respondents to assign a letter grade to their perception of the overall quality of health care services in Canada, including the federal government's performance in dealing with health care.

Of the 1000 people Ipsos Reid called, $85 \%$ agreed with the statement that Canada needs a comprehensive health care strategy for seniors, while only $12 \%$ agreed with the statement that Canada does not need to focus on a seniors' strategy. The survey has a margin of error of plus or minus 3.1 percentage points.

A majority of respondents $-78 \%$ - also agreed that the federal government has an important role to play in developing a national seniors' care strategy.

Only $41 \%$ of respondents think hospitals and long-term care facilities in their geographical area can handle the health care needs of seniors who won't be able to stay at home.

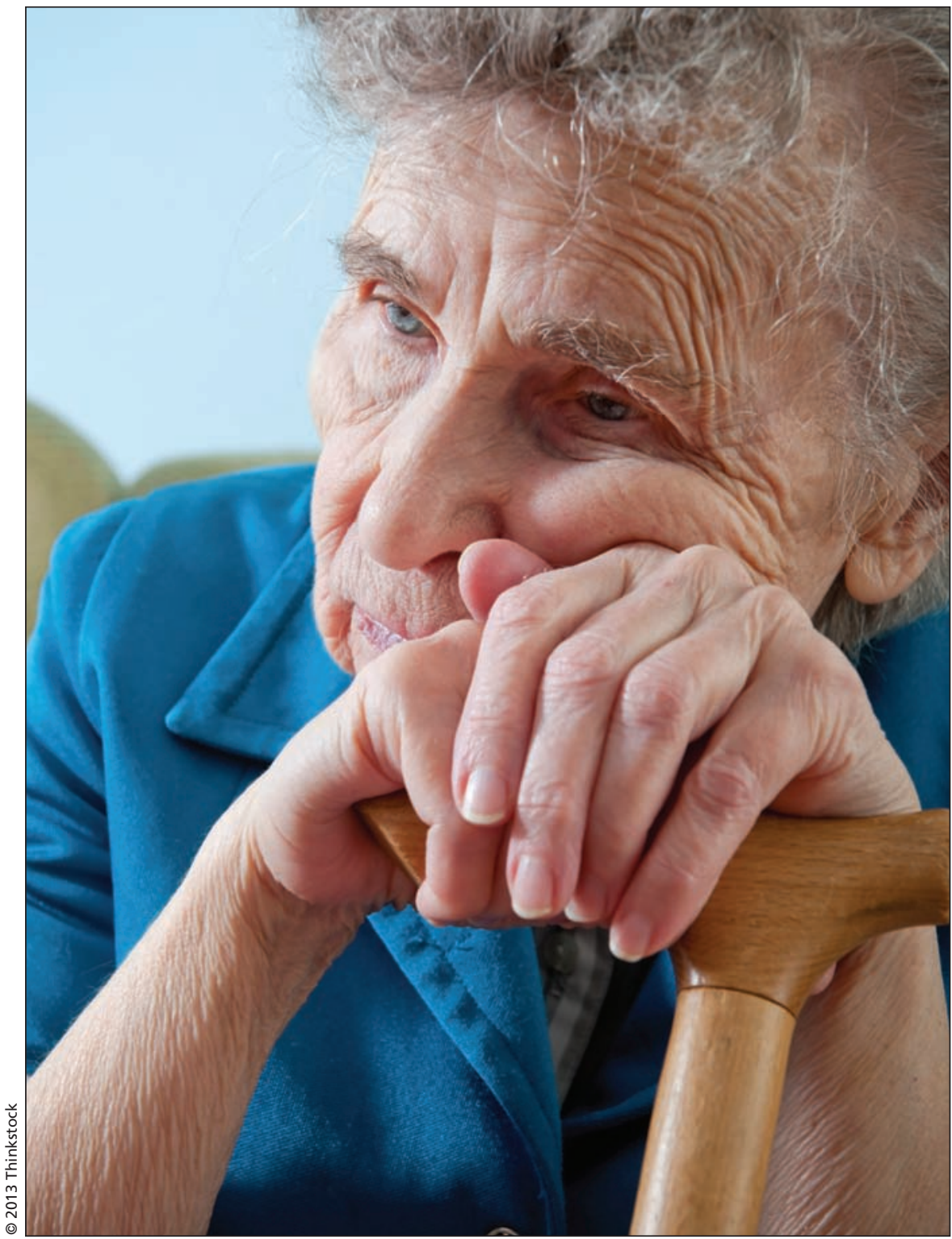

All levels of government must collaborate on a seniors' strategy, in light of the looming pressure that aging babyboomers will place on the health care system, says the CMA.

"The results of this year's CMA report card send a clear and direct message to policy-makers and public office holders that all levels of government need to act to address the demographic tsunami that is heading towards the health care system," Reid stated.

Most respondents assigned a B or an A grade to overall health care services in Canada, with $45 \%$ assigning a $\mathrm{B}$ to the quality of services available to them, and 30\% giving it an A. The respondents' perception of the quality of their health care system has neither improved nor declined greatly over the last five years, according to the results of the report card.

Respondents' assessment of how well the federal government has performed in dealing with health care is less 
favourable, however, with just $7 \%$ of Canadians awarding it an $\mathrm{A}$ on that score, $33 \%$ handing out a $\mathrm{B}$ and $35 \%$ giving Ottawa a $\mathrm{C}$, according to the report card. Another 19\% of Canadians give Ottawa a failing grade for its health care performance.

The CMA's emphasis on Ottawa's leadership in health care is taking place against the backdrop of the current Conservative government's reluctance to take on that role, preferring to leave health care policy to the provinces. However, the issue of policy direction on health care is expected to take more precedence in 2014, when the 10-year health accord reached in 2004 by the federal government and the provinces expires.

Under that agreement, Ottawa and the provinces and territories negotiated a schedule of federal transfer payments for health care and emphasized health quality benchmarks for critical health- care areas, such as cardiac care and joint replacement.

At the CMA general meeting, about 280 doctors representing the CMA's 78000 member physicians will vote on a slate of resolutions intended to drive the national association's policy agenda in the coming year. Delegates will also welcome the incoming 2013-14 president, Dr. Louis Francescutti, an Edmonton, Alta. emergency department physician and a professor in the School of Public Health at the University of Alberta in Edmonton. They will also elect the 2015-16 president of the association.

Francescutti, who before the meeting's formal opening chaired an education session on engaging patients in advance directives, has already been quoted in the media saying he believes it is time for Canadian doctors to reopen the discussion of their role in end-of-life care - one of the issues an expert panel addressed at the meeting. According to a 2007 policy, the CMA officially opposes doctor-assisted suicide and euthanasia.

In an education session for delegates about advanced care planning, experts from both Canada and the United States who are launching public awareness campaigns about the importance of end-oflife discussions urged doctors in the room to make their own advanced care plans.

"All of us are potentially patients," said Nathan Kottkamp, a Virginia lawyer and bioethicist who founded National Healthcare Decisions Day (Apr.16) in the United States. The national day revolves around a public awareness campaign urging the public and their health care providers to complete advanced care directives.

"If you haven't gone through it yourself, how can you help your patients go through it?" - Laura Eggertson, CMAJ

CMAJ 2013. DOI:10.1503/cmaj.109-4583 